\title{
WEPHREN: a global prison health research network
}

\begin{tabular}{|r|l|}
\hline Journal: & International Journal of Prisoner Health \\
\hline Manuscript ID & IJPH-03-2017-0014 \\
\hline Manuscript Type: & Editorial \\
\hline & \\
\hline
\end{tabular}

SCHOLARONE $^{\text {m }}$

Manuscripts 


\section{WEPHREN: a global prison health research network}

Inequality is widely recognised as an important global problem. Goal 10 of the United Nation's Sustainable Development Goals is to 'reduce inequality within and among countries' (United Nations, ND) and one of the key strategic objectives for the World Health Organisation (WHO) Europe's new health policy framework, Health2020, is 'improving health for all and reducing health inequalities' (WHO, 2013). If we are to tackle health inequalities effectively then addressing the health needs of people in prison will be an essential element of any action plan: people in prison and others in the criminal justice system often come from marginalised and under-served communities in the wider population and so by tackling health inequalities in this population, we can address wider health inequalities, benefitting not only those in prisons but wider society too- we describe this as the 'community dividend'.

Few readers of the International Journal of Prisoner Health would dispute the important role that research into the health of people in prison plays in improving this population's health and thus contributing to reducing health inequalities. Research, for example, plays a key role in illuminating the important public health issues in prisons and in informing the development of appropriate health and social care services. The published literature has provided important evidence demonstrating the considerable health needs of prisoners and highlighting the need for effective health services based on the needs of these particular individuals rather than assuming their needs are the same as the communities in which the prisons are sited. For example, a number of systematic reviews synthesising the evidence have shown that when compared to the general population, the prevalence rates of a number of health problems are considerably higher in people in prison. People in prison have rates of psychotic illnesses and major depression two to four times higher, and rates of antisocial personality disorder are about 10 ten times higher than the general population (Fazel and Danesh, 2002). Compared to the general population of the United States of similar age, men in prison are 2-10 times more likely to be drug dependent and women in prison are two to four times as likely to be alcohol dependent and at least a 13 times more likely to be drug dependent (Fazel et al., 2006). Prevalence rates for infectious diseases are also much higher than those found in the community; epidemiological studies of prison populations in most countries have consistently reported rates of HIV infection that are greater than those in the general population as are those of hepatitis B and C viruses and tuberculosis (Dolan et al., 2016). Noncommunicable diseases are also an issue for those in prison with rates of physical inactivity, poor diet and smoking higher than those found in the community (Ritter et al., 2011; Herbert et al,. 2012). The evidence also demonstrates that imprisoned women had poorer outcomes of pregnancy than the general population (Bard et al., 2016).

The increase in prison health research in recent years is therefore an important and positive development, highlighting the need for and informing the process of health service development in prisons. However this rise in publications has been uneven, coming from particular countries, especially high income countries, rather than every country. For example, in the WHO European Region alone, it is clear to see that the development in the evidence base has not been uniform across Member States; a rapid search of PubMed using the term prison* and the country of interest showed that since the beginning of 2000, 501 papers had been 
published relating to prison health in Germany, 318 in France, yet only five in Albania, three in Uzbekistan and two in Turkmenistan. Hence a new inequality has emerged very clearly.

This inequity between countries is neither desirable nor inevitable. We believe that the development of the WorldwidE Prison Health Research \& Engagement Network (WEPHREN) has the potential to improve the evidence base for health and health service delivery within prison settings and therefore, very importantly, to improve the health and wellbeing of people in prison, reduce health inequalities and to influence prison health policy. WEPHREN is led by the World Health Organization Health in Prisons Programme's UK Collaborating Centre (WHO HIPP UK CC) which is located in the National Health and Justice Team at Public Health England https://www.gov.uk/government/collections/public-health-in-prisons. WEPHREN was created by WHO HIPP UKCC in collaboration with the World Health Organization (Europe) Health in Prisons Programme and discussion with member states. Those working for many years in years in national and international prison health policy development and those working in prison health research had been struck by the inequities in output for different reasons. Those striving to make the case for new progressive policies in prison health care found that the evidence to support developments was lacking in many countries; those researchers synthesising the evidence found that time and again that their systematic reviews mostly included studies from high income countries - there was a shocking lack of research from low and middle income countries.

A network can be defined as: 'a cooperative structure where interconnected groups or individuals coalesce around a shared purpose on the basis of trust and reciprocity' [9]. Our shared purpose is improve the health of those in prison through high quality policy- and practitioner-relevant research and by developing the capacity of all those working in prison settings. Our vision of WEPHREN therefore is an inclusive one: it will not be limited to academic researchers but will engage all those with an interest in the health of people in prison - for example, health practitioners, prison services, prisoners themselves, policy makers, nongovernmental organisations and public health organisations. We believe this broad approach is important in order to ensure an increased quantity and quality of policy maker and practitioner relevant health research that enables countries to better define and address the health needs of people in prison, be that through better informed policy or more effective evidence-based interventions at local or national level.

In the coming years, WEPHREN will provide:

- A forum for all stakeholders interested in prison health across the world to exchange ideas and to work together;

- A network for researchers to develop collaborative multi-centre, multi country research proposals;

- A means of disseminating important research findings across the world;

- A platform for developing the skills of health professionals and researchers;

- A vehicle to drive development of effective collaborative networks within and between countries;

- An opportunity for supported professional development of researchers, healthcare professionals and other collaborators. 
WEPHREN will therefore play a key role in addressing issues of equity and reducing the current disparity in research capacity and outputs between countries. The network will lead to increased collaboration between researchers in different countries and between researchers, policy makers and practitioners. In parallel, it will also help create a cadre of appropriately trained health researchers; it is clear that if research is to be developed, research capacity must also be developed too. Indeed, WEPHREN's capacity development ambitions go beyond purely developing research skills; WEPHREN will serve as a platform for broader knowledge and skills development and sharing between all professionals with an interest in prison health.

WEPHREN has a clear purpose and structures in place to ensure good governance and to facilitate intelligence sharing and the development of a virtual community committed to improving the health of people in prisons. However, the key ingredient missing in the recipe for a successful network is a critical mass (The Health Foundation, 2014). We therefore encourage all readers, wherever in the world they are located, to participate in this exciting new international network and ask them to contact us at WEPHREN@phe.gov.uk or to go to the newly established network website at www.wephren.org and register as a member. As the network evolves there will be opportunities for those involved to contribute to the longer term vision for the network so that it supports and reflects the needs and interests of its members.

\section{REFERENCES}

Bard E, Knight M, Plugge E. (2016) The outcomes of pregnancy among imprisoned women and the effect of perinatal health care service on these outcomes: a systematic review. $B M C$ Pregnancy and Childbirth, 16: 285.

Dolan K, Wirtz AL, Moazen B, Ndeff o-mbah M, Galvani A, Kinner SA, Courtney R, McKee M, Amon JJ, Maher L, Hellard M, Beyrer C, Altice FL. (2016) Global burden of HIV, viral hepatitis, and tuberculosis in prisoners and detainees. Lancet, 388: 1089-102.

Fazel S, Bains P, Doll H. (2006) Substance abuse and dependence in prisoners: a systematic review. Addict, 101: 181-91.

Fazel S, Danesh J. (2002) Serious mental disorder in 23000 prisoners: a systematic review of 62 surveys. Lancet, 359: 545-50.

The Health Foundation (2014) Effective networks for improvement- Developing and managing effective networks to support quality improvement in healthcare. Online: http://www.health.org.uk/publication/effective-networks-improvement [Accessed 27/03/2017].

Herbert K, Plugge E, Foster C, Doll H. (2012) A systematic review of the prevalence of risk factors for non-communicable diseases in worldwide prison populations. Lancet, 379 (9830):1975-82. 
Ritter C, Stover H, Levy M, Etter J-F, Elger B. (2011) Smoking in prisons: the need for effective and acceptable interventions. J Public Health Pol, 32: 32-45.

United Nations (ND) Sustainable Development Goals. Online:

https://sustainabledevelopment.un.org/?menu=1300 [Accessed 27/03/2017]

World Health Organization (2013) Regional Office for Europe of the World Health Organization. Health 2020. A European policy framework and strategy for the 21st century. 